Research Article

\title{
The Impact of Step Recommendations on Body Composition and Physical Activity Patterns in College Freshman Women: A Randomized Trial
}

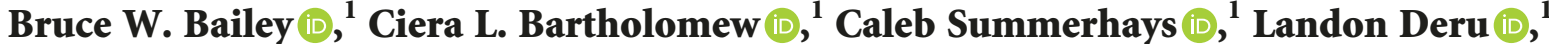 \\ Sharla Compton, ${ }^{1}$ Larry A Tucker $\mathbb{D}^{1},{ }^{1}$ James D. LeCheminant $\mathbb{D}^{2},{ }^{2}$ and Joseph Hicks ${ }^{1}$ \\ ${ }^{1}$ Department of Exercise Sciences, Brigham Young University, Provo, UT, USA \\ ${ }^{2}$ Department of Nutrition, Dietetics \& Food Science, Brigham Young University, Provo, UT, USA
}

Correspondence should be addressed to Bruce W. Bailey; bruce_bailey@byu.edu

Received 7 August 2019; Accepted 25 October 2019; Published 1 December 2019

Academic Editor: David H. St-Pierre

Copyright (c) 2019 Bruce W. Bailey et al. This is an open access article distributed under the Creative Commons Attribution License, which permits unrestricted use, distribution, and reproduction in any medium, provided the original work is properly cited.

\begin{abstract}
Purpose. Transitioning from high school to college generally results in reduced physical activity and weight gain at a rate that is higher than the general population. The purpose of this study was to examine the effects of three progressively higher step recommendations over 24 weeks on changes in body weight and body composition. Methods. Ninety-two freshmen college women wore a multifunction pedometer for 24 weeks after being randomly assigned to a daily step level: 10,000, 12,500, or 15,000. Pedometer data were downloaded every two weeks and participants were counseled on meeting their step recommendation. Body weight and body composition were assessed at baseline and 24 weeks. Body composition was assessed by dual X-ray absorptiometry. Results. On average, women took 10,786 $\pm 1501,12,650 \pm 2001$, and 13,762 \pm 2098 steps per day for the 10,000-, 12,500-, and 15,000-step groups, respectively $(F=15.48, P<0.0001)$. Participants gained $1.4 \pm 2.6,1.8 \pm 2.1$, and $1.4 \pm 2.1 \mathrm{~kg}$ for the 10,000 -, $12,500-$, and 15,000 -step groups, respectively $(F=37.74, P<0.0001)$. Weight gain was not significantly different between groups $(F=0.18, P=0.8385)$. There was also no difference in fat weight gain $(F=0.41, P=0.7954)$. Discussion. A step recommendation beyond 10,000 does not prevent weight or fat gain over the first year of college. Future research should focus on either intensity of physical activity or the addition of dietary interventions to prevent weight gain during the first year of college.
\end{abstract}

\section{Introduction}

College students represent a high-risk population for weight gain and obesity (1-3). This is partly due to the fact that many college students are in a critical transitional life stage and are establishing patterns that may persist throughout adulthood [1]. Studies of college students indicate that a $1-4 \mathrm{~kg}$ weight gain is common during their first 2 years of college with a recent prospective study suggesting some students gain as much as $20.8 \mathrm{~kg}$ over the course of four years of college $[2,3]$.

Though not always a straightforward relationship, physical activity has been shown to be significantly associated with weight and body fat in women [4-7]. Reduced physical activity has a negative impact on energy balance and thus may lead to weight gain if dietary compensation does not take place. Physical activity can prevent weight gain by increasing energy expenditure, thereby adjusting for small positive energy imbalances [8]. Physical activity tends to decline in the transition from high school to college, [9] and this decline could partially explain the observed weight gain during the first years of college.

Using a pedometer to count steps is an easy method to track and promote physical activity [10]. There is a growing body of research demonstrating the ability of pedometers to promote activity, including one investigation which showed that participants increased the number of steps taken by $26.9 \%[11,12]$. These same studies also demonstrated that 
pedometers can be used to decrease body mass index $[11,12]$. While these investigations demonstrate the utility of pedometers to promote physical activity in the general population, their value in preventing weight gain in college students is still relatively unknown.

The impact of steps on body weight during the freshman year was evaluated by LeCheminant et al. [13]. The results from this study demonstrated that there was no difference over the academic year in weight gain between students randomized to achieve 10,000 steps per day and those in the control group [13]. However, this study did not assess the steps of the students at baseline in the control or intervention groups and failed to evaluate the steps of the participants in the control group throughout the duration of the study. As a result, researchers speculated that it might be possible that students were already achieving 10,000 steps per day, so the intervention might not have been enough to prevent weight gain.

The purpose of this investigation was to evaluate the impact of 3 progressively higher step recommendations on preventing weight and body fat gain during the first university academic year (24 weeks) in women. The step recommendations were $10,000,12,500$, and 15,000 steps per day; 12,500 and 15,000 represent a $25 \%$ and $50 \%$ increase in daily physical activity. Additionally, this study sought to control other potential confounding factors of increased physical activity, such as eating behaviors, and diet. The original hypothesis of the study was that there would be a dose response relationship between step recommendation and body weight, with higher numbers of steps predicting less weight and fat weight gain over 24 weeks compared to lower numbers of steps.

\section{Methods}

2.1. Design. The study was a three-arm randomized trial. Participants were randomized to one of three step recommendations that included 10,000, 12,500, and 15,000 steps per day ( 6 days per week) over 24 weeks. These step recommendations represented an incremental $25 \%$ increase in physical activity. Participants were provided encouragement and support to achieve the recommended level of steps; however, no participant was dropped for not achieving the step recommendation. All participant identification numbers were randomized at the beginning of the study by the senior investigator using PC-SAS. The randomized intervention allocation list was kept concealed from study personnel by the senior investigator until baseline testing was complete and the participant number was assigned. Once the participant number was assigned, the intervention allocation was revealed by the senior investigator. The study was approved by the institution review board and all participants gave informed consent before participating.

2.2. Participants. Participants included 120 college women aged 18-22 years who were in their first year of college. A health history questionnaire was used to determine participants' health status and ability to participate in moderate- to-vigorous activity (MVPA) without limitations. Additionally, participants who were up to six months postpartum or who were planning to become pregnant in the next 8 months were excluded from the study. Women taking any medications that alter metabolism, who had a body mass index below $18.5 \mathrm{~kg} / \mathrm{m}^{2}$, or who took more than 11,000 steps per day at baseline were excluded from the study. The 11,000 -step exclusion was set to prevent participants from being randomized into the 10,000-step group who were already exceeding the step counts of the other groups [14]. We used 11,000 steps instead of 10,000 steps to exclude participants because we assumed that physical activity would be higher at the beginning of school, as students tend to have more free time and were getting used to campus life. Following randomization into one of the three step groups, participants were instructed not to discuss their step count assignment with other participants. The modes of recruitment included flyers, classroom announcements, booths, social media, and word of mouth.

2.3. Procedures. Once study eligibility was confirmed, baseline assessments were completed. The baseline assessment included three 24-hour dietary recalls, a DXA scan, anthropometric measurements of weight and height, and physical activity. To assess physical activity, participants were given an accelerometer and pedometer and instructed to wear them for 4 consecutive days. Accelerometers were used to supplement pedometers because accelerometers provide richer data describing physical activity patterns, such as time spent in sedentary, light, and MVPA.

Following the baseline assessments, if the person's average daily steps exceeded 11,000 per day, the participant was dropped from the study. Eligible participants were then randomized to a step count. Participants were instructed to meet their assigned step goal 6 out of 7 days of the week, and text messages were sent to the participants every day to encourage them to meet their step goal. They were not, however, restricted to their step count assignment since this seemed unreasonable. Participants returned to the lab every two weeks to download their step count information and to complete a sham questionnaire about stress. This questionnaire was used to divert attention away from body weight so that participants did not anticipate a weight-related outcome for the study.

In addition to health and stress questionnaires, participants also completed ten 24-hour multiple-pass dietary recalls throughout the duration of the study. Three recalls were performed randomly at baseline and an additional recall was completed every 4 weeks during the intervention period ( 7 times total). The day of the week for this recall was chosen randomly.

All the assessments that were performed at baseline were completed again either at the end of the intervention or during the intervention period. Physical activity was assessed continually using an assigned pedometer, and for 4 consecutive days during weeks 20 to 22 , using an accelerometer. Weight, height, and body composition were assessed during the last week of the intervention. 
2.4. Measurement of Anthropometrics. Height was measured to the nearest $0.1 \mathrm{~cm}$ using a wall-mounted stadiometer (SECA, Chino, CA). Weight was measured to the nearest $0.1 \mathrm{~kg}$ using a digital scale (Tanita, Arlington Heights, Illinois). GE iDXA (GE, Fairfield, CT) was used to assess fatfree mass, fat mass, lean mass, percent body fat, and visceral adipose tissue [15-17]. Visceral fat was calculated using the CoreScan application of the GE iDXA $[18,19]$. Calibration of the DXA scan took place at the beginning of each testing day using a manufacturer-provided calibration block. Scans were analyzed using Encore software version 17.

2.5. Measurement of Physical Activity. Participants were issued an Omeron HJ-720-IT pedometer. Pedometers have been used in research to both encourage and track steps [10]. They were instructed to wear the pedometers throughout the day for four days at baseline (two weekdays and two weekend days) and for the duration of the 24 weeks of the study [20]. The pedometer was worn at all times during the study, with the exception of showering or other water related activities. This data was downloaded every two weeks.

ActiGraph GT3X accelerometers were also used to assess physical activity and were worn by the participants over a four-day period (two weekdays and two weekend days) at baseline and then again between weeks 20 and 22 of the intervention period. The participants were instructed to wear the accelerometers on their hip at the level of the umbilicus and above the anterior superior iliac spine, opposite the hip of the pedometer. They were also instructed to wear the accelerometer day and night with the exception of water activities. Accelerometers give information on time and intensity of activity and have been shown to be accurate in determining differences in low-moderate and high-intensity activity levels [21-24]. The day's data was considered complete if they wore the accelerometer $75 \%$ of the time between 7 a.m. and 11 p.m. Nonwear time was conservatively defined as any string of at least 20 consecutive minutes with zero acceleration. Data was collected in 60 second epochs. Physical activity intensity levels were categorized using the following cut-points: vigorous activity ( $>5999$ counts/min), moderate activity (2020-5999 counts/min), light activity (100-2019 counts/min), and sedentary (0-100 counts/min) [25].

2.6. Measurement of Diet. Dietary intake was assessed by multiple uses of the Automated Self-Administered 24-hour Dietary Recall (ASA24) survey provided by the U.S. National Cancer Institute in conjunction with the National Institutes of Health (NCI and NIH). Using the Web-based ASA24, the participants were asked to record everything they ate and drank in the previous 24 hours. The ASA24 includes a database of food items separated by food group. The participants were instructed by both audibly and by typed prompts in how to record meals and snacks. The serving size choices were supplemented with pictures. The system ensured that participants had included all foods consumed during the previous 24 hours by using repeated prompts for "oft-forgotten foods," such as ketchup, soda, and butter.
ASA24 has little error variance compared to interviewerbased recalls and is more cost-effective $[26,27]$.

2.7. Data Analysis. Sample size was estimated a priori and based on the comparison between the 10,000- and 15,000step groups for body weight. We estimated a $2 \mathrm{~kg}$ weight difference between groups with a common standard deviation of $2.8 \mathrm{~kg}$ [28]. Beta was set at 0.20 and alpha was set at 0.05 . Based on these assumptions, 33 participants were needed in each group to have $80 \%$ power. We anticipated a $15 \%$ dropout rate and thus recruited 40 participants in each group for a total of 120 participants.

Means and standard deviations were reported for all variables of interest. A mixed effects repeated measures analysis of variance was used to analyze the results of physical activity, body composition, and diet. Results were evaluated to assess the interactive and main effects of period and step group (10,000, 12,500, and 15,000 steps). A similar analysis was performed to evaluate pedometer measured average steps per day by step group and month of the study. The least squared means procedure was used to further evaluate any significant main and interactive effects. For both, the accelerometer-measured physical activity and diet, assessment days were averaged across the period (baseline and follow-up) prior to analysis. PC-SAS version 9.4 was used for the mixed effects modeling.

\section{Results}

3.1. Participants. Characteristics of the participants are described in Figure 1 and Table 1. A total of 512 women were assessed for eligibility and 120 were randomized into one of the three step groups $(10,000$ steps $(n=40), 12,500$ steps $(n=40)$, and 15,000 steps $(n=40))$. Of the 120 participants, 92 completed the study. Dropout was not equal between the groups with the 15,000-step group having the highest dropout rate. However, there were no differences in age, BMI, percent body fat, steps per day, or energy intake between participants who finished the study and those who did not.

3.2. Steps/Physical Activity. Figure 2 displays the pedometer downloaded steps per day over the course of the study. The average daily steps accumulated by each step count were $10,786 \pm 1501,12,650 \pm 2001$, and $13,762 \pm 2098$ steps per day for the 10,000-, 12,500-, and 15,000-step groups, respectively, and all three counts were significantly different from the others $(P<0.0001)$. There was no significant stepcount-by-month interaction observed. However, average steps per day tended to increase over the course of the study with the exception of December, which resulted in the lowest averages of the study for all three groups (see Figure 2).

Accelerometer physical activity data are presented in Table 2. A period (baseline or follow-up) by step group interaction was observed for nonsedentary time, MVPA, and steps but was not significant for light PA $(P=0.0505)$. Follow-up tests revealed that nonsedentary time (all light activity and MVPA) did not change from baseline to follow- 


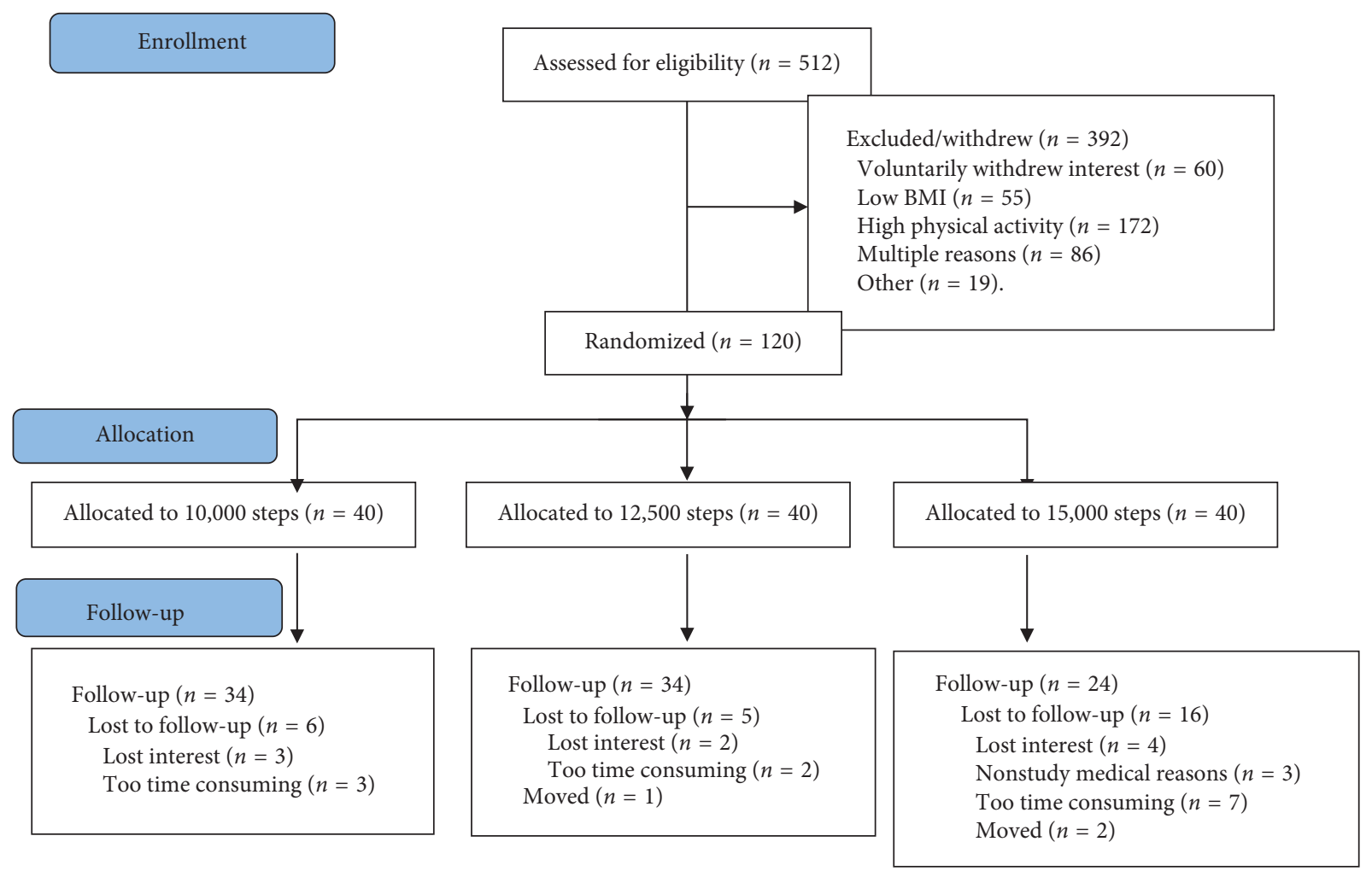

FIgURe 1: Participant flow diagram.

Table 1: Demographic data by step group at baseline.

\begin{tabular}{|c|c|c|c|c|c|c|c|c|c|c|}
\hline & \multicolumn{2}{|c|}{$\begin{array}{l}10,000 \text { steps } \\
(n=40)\end{array}$} & \multicolumn{2}{|c|}{$\begin{array}{c}12,500 \text { steps } \\
(n=40)\end{array}$} & \multicolumn{2}{|c|}{$\begin{array}{c}15,000 \text { steps } \\
(n=40)\end{array}$} & \multicolumn{2}{|c|}{$\begin{array}{c}\text { Combined } \\
(n=120)\end{array}$} & \multirow[t]{2}{*}{$F$} & \multirow[t]{2}{*}{$P$} \\
\hline & $M$ & $\mathrm{SD}$ & $M$ & SD & $M$ & SD & $M$ & $\mathrm{SD}$ & & \\
\hline Age (yrs) & 18.0 & 0.2 & 18.1 & 0.3 & 18.0 & 0.4 & 18.1 & 0.3 & 0.36 & 0.69 \\
\hline BMI $\left(\mathrm{kg} / \mathrm{m}^{2}\right)$ & 23.5 & 2.7 & 22.7 & 2.14 & 23.2 & 2.6 & 23.1 & 2.5 & 0.87 & 0.42 \\
\hline Body fat $\%$ & 34.0 & 5.3 & 32.7 & 4.1 & 33.0 & 5.2 & 33.2 & 4.9 & 0.79 & 0.45 \\
\hline Average steps at baseline & 8082 & 1608 & 8375 & 1537 & 8213 & 1444 & 8225 & 1512 & 0.35 & 0.71 \\
\hline
\end{tabular}

Note. $F$ and $P$ values refer to the comparison of groups at baseline.

up in the 10,000-step group but increased by 43 minutes per day in the 12,500-step group and by 77 minutes per day in the 15,000-step group. MVPA changed significantly from baseline in all three groups, increasing by 15 minutes, 28 minutes, and 34 minutes in the 10,000-, 12,500-, and 15,000step groups, respectively.

3.3. Body Composition and Weight. Table 3 shows data collected from the DXA scans in relation to body composition and weight. On average women gained $1.5 \pm 2.3 \mathrm{~kg}$ over the course of the study $(F=37.61, P<0.0001)$ with no significant difference between the 10,000-, 12,500-, and 15,000 -step groups. DXA scans showed that $0.7 \pm 1.7 \mathrm{~kg}$ of this weight gain was fat and $0.8 \pm 1.1 \mathrm{~kg}$ was lean body mass (Ps $<0.001$ ). Thus, weight gain was $44 \%$ fat mass and $56 \%$ lean. Visceral adipose tissue mass and volume were low and did not change over the course of the 6 months. There was no period-by-step-group interaction for any body composition variable.
3.4. Diet. Table 4 describes the dietary data for participants who completed the study. The average total caloric intake at baseline was $2115 \pm 527 \mathrm{kcal}$. There was no main effect for period or step group and there were no interactive effects between period and step group. There was no main effect in total calories consumed from baseline to follow-up. The total fat and $\mathrm{CHO}$ intakes were not statistically different between groups. However, the difference in protein intake was significant $(P<0.05)$, with the 12,500 -step group consuming less protein at follow-up than the other groups.

\section{Discussion}

The goal of the study was to evaluate if progressively exceeding the recommended step count of 10,000 steps per day (in $25 \%$ increments) would attenuate weight and fat accumulation in college freshmen women. Regardless of the overall increase in steps per day and consistent separation in steps between the three step groups, women gained about $1.5 \mathrm{~kg}$ as a whole over the 6 months of the study (Table 3 ). 


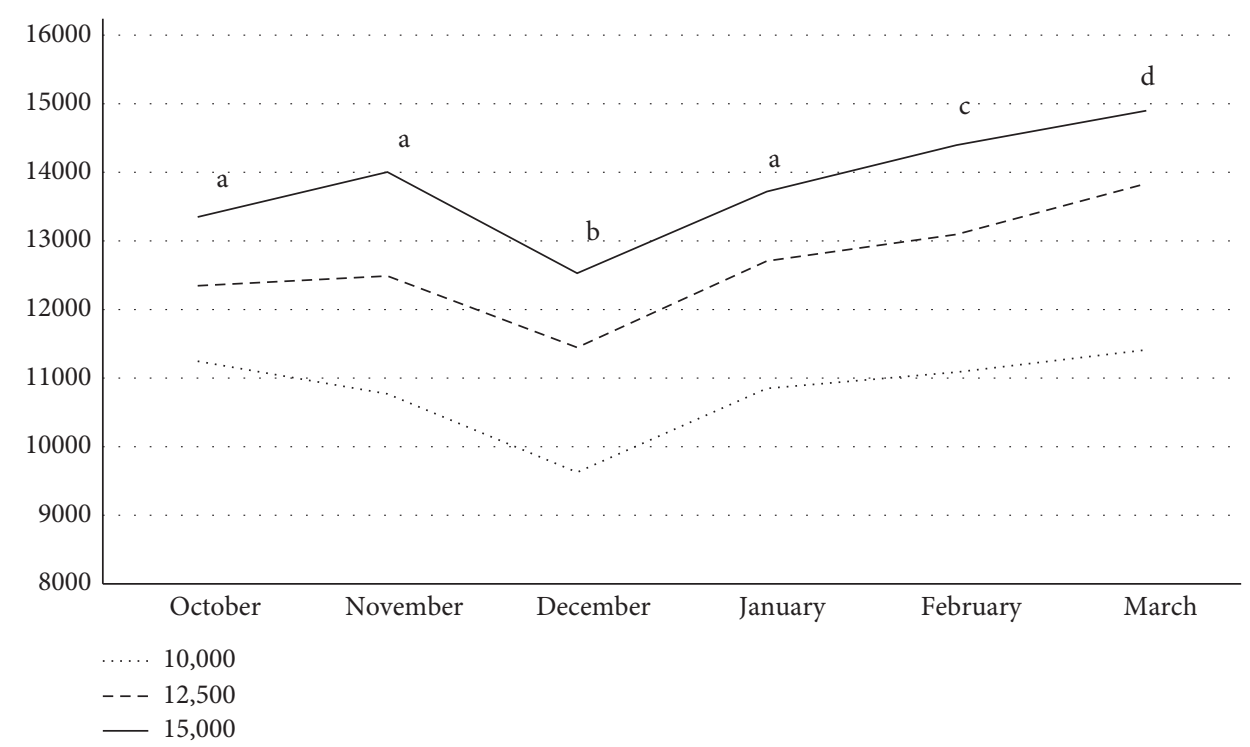

FIgURE 2: Average steps per day by month over the course of 24 weeks in 1st year college women. There was no month by step recommendation interaction observed. The average steps per day for all three step recommendation groups were different $(P<0.05)$. a, b, $\mathrm{c}, \mathrm{d}$ : average steps per day in months with different letters are significantly different $(P<0.05)$. For example, average steps in October were higher than those in December but lower than those in February and March.

TABle 2: Physical activity data by step group measured by actigraphy.

\begin{tabular}{|c|c|c|c|c|c|c|c|c|c|c|c|c|c|c|}
\hline & \multicolumn{4}{|c|}{$\begin{array}{c}10,000 \text {-step group } \\
(n=34)\end{array}$} & \multicolumn{4}{|c|}{$\begin{array}{l}12,500 \text {-step group } \\
(n=34)\end{array}$} & \multicolumn{4}{|c|}{$\begin{array}{c}15,000 \text {-step group } \\
(n=24)\end{array}$} & \multirow{3}{*}{$F$} & \multirow{3}{*}{$P$} \\
\hline & \multicolumn{2}{|c|}{ Baseline } & \multicolumn{2}{|c|}{ Follow-up } & \multicolumn{2}{|c|}{ Baseline } & \multicolumn{2}{|c|}{ Follow-up } & \multicolumn{2}{|c|}{ Baseline } & \multicolumn{2}{|c|}{ Follow-up } & & \\
\hline & $M$ & $\mathrm{SD}$ & $M$ & $\mathrm{SD}$ & $M$ & $\mathrm{SD}$ & $M$ & $\mathrm{SD}$ & $M$ & $\mathrm{SD}$ & $M$ & $\mathrm{SD}$ & & \\
\hline Steps per day & 9232 & 2141 & $11066^{* a}$ & 2360 & 9992 & 907 & $13638^{* b}$ & 2135 & 9571 & 2264 & $14557^{* \mathrm{c}}$ & 2338 & 9.52 & $<0.001$ \\
\hline Aerobic steps & 3887 & 1764 & $5351^{* a}$ & 2043 & 4638 & 1876 & $7601^{* b}$ & 2373 & 4603 & 1597 & $7619^{* b}$ & 2028 & 4.94 & 0.009 \\
\hline Nonsedentary (min) & 309.1 & 61.3 & $322.2^{* \mathrm{a}}$ & 59.3 & 313.9 & 64.2 & $353.7^{* \mathrm{~b}}$ & 57.5 & 301.6 & 43.7 & $370.7^{* \mathrm{~b}}$ & 57.6 & 6.59 & 0.002 \\
\hline Light activity (min) & 255.6 & 56.0 & 254.8 & 58.5 & 257.3 & 66.6 & 269.8 & 62.8 & 246.4 & 45.3 & $282.5^{*}$ & 58.5 & 3.10 & 0.050 \\
\hline $\operatorname{MVPA}(\min )$ & 53.5 & 56.0 & $67.5^{* \mathrm{a}}$ & 17.5 & 56.7 & 17.5 & $84.2^{* \mathrm{~b}}$ & 19.1 & 55.3 & 21.4 & $88.7^{* \mathrm{~b}}$ & 17.7 & 6.63 & 0.002 \\
\hline
\end{tabular}

Notes. $F$ and $P$ values refer to the period-by-step-group interaction. ${ }^{*}$ Significant difference from baseline to follow-up $(P \leq 0.05)$. ${ }^{\mathrm{a}, \mathrm{b}, \mathrm{c}} \mathrm{Means}$ with different letters were statistically different at follow-up $(P<0.05)$. There was no mean difference in any of the variables at baseline.

TABLE 3: Body composition results by step group.

\begin{tabular}{|c|c|c|c|c|c|c|c|c|c|c|c|c|c|c|}
\hline & \multicolumn{4}{|c|}{$\begin{array}{c}\text { 10,000-step group } \\
(n=34)\end{array}$} & \multicolumn{4}{|c|}{$\begin{array}{c}\text { 12,500-step group } \\
(n=34)\end{array}$} & \multicolumn{4}{|c|}{$\begin{array}{c}15,000 \text {-step group } \\
(n=24)\end{array}$} & \multirow{3}{*}{$F$} & \multirow{3}{*}{$P$} \\
\hline & \multicolumn{2}{|c|}{ Baseline } & \multicolumn{2}{|c|}{ Follow-up } & \multicolumn{2}{|c|}{ Baseline } & \multicolumn{2}{|c|}{ Follow-up } & \multicolumn{2}{|c|}{ Baseline } & \multicolumn{2}{|c|}{ Follow-up } & & \\
\hline & $M$ & $\mathrm{SD}$ & $M$ & SD & $M$ & $\mathrm{SD}$ & $M$ & SD & $M$ & SD & $M$ & SD & & \\
\hline BMI $\left(\mathrm{kg} / \mathrm{m}^{2}\right)$ & 23.5 & 2.7 & $23.9^{*}$ & 2.2 & 22.7 & 2.1 & 23.2 & 2.2 & 23.2 & 2.6 & 23.7 & 2.0 & 0.15 & 0.857 \\
\hline Body fat $\%$ & 34.1 & 5.3 & 34.0 & 4.5 & 32.7 & 4.4 & 33.1 & 4.1 & 32.9 & 5.2 & 33.5 & 3.9 & 0.92 & 0.401 \\
\hline Total mass (kg) & 65.0 & 7.6 & $66.3^{*}$ & 5.8 & 61.5 & 6.8 & $63.0^{*}$ & 6.8 & 63.6 & 8.2 & $65.3^{*}$ & 7.1 & 0.27 & 0.762 \\
\hline Total fat mass $(\mathrm{kg})$ & 22.4 & 5.8 & 22.8 & 4.7 & 20.2 & 4.1 & $21.0^{*}$ & 3.9 & 21.2 & 5.3 & $22.0^{*}$ & 4.2 & 0.66 & 0.519 \\
\hline Total lean mass (kg) & 40.2 & 3.1 & $41.0^{*}$ & 2.8 & 38.8 & 4.1 & $39.7^{*}$ & 4.2 & 40.0 & 4.3 & $40.8^{*}$ & 4.1 & 0.07 & 0.933 \\
\hline VAT mass (g) & 153.0 & 131.0 & 154.1 & 149.2 & 118.3 & 94.6 & 128.0 & 128.4 & 154.0 & 112.2 & 167.8 & 108.7 & 0.46 & 0.634 \\
\hline VAT volume $\left(\mathrm{cm}^{3}\right)$ & 162.2 & 148.4 & 163.3 & 158.1 & 125.4 & 100.2 & 135.7 & 136.1 & 163.2 & 119.0 & 177.8 & 115.2 & 0.46 & 0.634 \\
\hline
\end{tabular}

Notes. $F$ and $P$ values refer to the period-by-step-group interaction. ${ }^{*}$ There was a significant main effect for period. Baseline means are different from followup $(P<0.05)$. There were no baseline differences between groups. There were no follow-up differences between groups.

The average weight gain observed was within the range of weight gain previously reported in other studies of college students. While the "Freshman 15" has been proven to be a myth for most people, a 1 to $4 \mathrm{~kg}$ average weight gain is commonly observed during the first academic year
$[1,2,8,29]$. These results also do not seem to be explained by diet, since there was no difference in energy intake between the three step groups. However, like most assessments of dietary intake, underreporting is common and interindividual variability tends to be large which may account 
TABLE 4: Baseline and follow-up diet by step group.

\begin{tabular}{|c|c|c|c|c|c|c|c|c|c|c|c|c|c|c|}
\hline & \multicolumn{4}{|c|}{$\begin{array}{c}\text { 10,000-step group } \\
(n=34)\end{array}$} & \multicolumn{4}{|c|}{$\begin{array}{c}\text { 12,500-step group } \\
(n=34)\end{array}$} & \multicolumn{4}{|c|}{$\begin{array}{c}15,000 \text {-step group } \\
(n=24)\end{array}$} & \multirow{3}{*}{$F$} & \multirow{3}{*}{$P$} \\
\hline & \multicolumn{2}{|c|}{ Baseline } & \multicolumn{2}{|c|}{ Follow-up } & \multicolumn{2}{|c|}{ Baseline } & \multicolumn{2}{|c|}{ Follow-up } & \multicolumn{2}{|c|}{ Baseline } & \multicolumn{2}{|c|}{ Follow-up } & & \\
\hline & $M$ & SD & $M$ & SD & $M$ & SD & $M$ & $\mathrm{SD}$ & $M$ & SD & $M$ & SD & & \\
\hline Kcals & 2028 & 451 & 2056 & 396 & 2221 & 551 & 1954 & 347 & 2196 & 772 & 2139 & 381 & 1.81 & 0.17 \\
\hline Protein & 72 & 19 & 76 & 24 & 79 & 22 & $65^{*+}$ & 13 & 69 & 20 & 77 & 23 & 3.65 & 0.03 \\
\hline Carbohydrate & 263 & 73 & 262 & 56 & 299 & 92 & 261 & 53 & 275 & 69 & 274 & 52 & 1.63 & 0.19 \\
\hline Total fat & 79 & 22 & 81 & 17 & 82 & 26 & 75 & 16 & 95 & 75 & 85 & 21 & 0.26 & 0.77 \\
\hline
\end{tabular}

Note. $F$ and $P$ values refer to the period-by-step-group interaction. ${ }^{*}$ Statistically different from baseline in the 12,500 -step group. ${ }^{+}$Statistically different at follow-up in the 10,000-, 12,500-, and 15,000-step groups.

for the lack of any observed difference between the three conditions.

The lack of attenuation in weight gain between step groups was surprising, since physical activity progressively increased with each step recommendation and physical activity increases energy expenditure and alters energy balance. One limitation in using steps to increase physical activity is that all steps were counted the same regardless of the intensity of the activity being performed. Thus, light steps were counted the same as vigorous steps. This could explain the lack of separation in weight gain between groups, because the majority of the increased activity in this study came from light activity and there was no change in vigorous activity. Thus, one explanation for the lack of separation in weight gain between groups might be that the activity was less intense and did not alter energy balance sufficiently to have a meaningful impact on body weight. Another explanation could be due to the normal physical maturation that occurs within this age group.

LeCheminant et al. evaluated how the recommendation of 10,000 daily steps impacted weight gain during the freshman year in women. Both the intervention and control groups gained a similar amount of weight $(1.0 \pm 2.5 \mathrm{~kg})$ [13] These results are similar to those observed in our study, but we observed no impact of steps beyond the 10,000-step count recommendation. It is possible that exceeding a certain step count does not result in more benefit on body weight or fat. An observation study of college women demonstrated that steps per day predicted body weight up to around 11,000 steps per day and that going beyond this level of habitual steps did not predict body weight or body fat [6]. Our study supports these findings and suggests that altering step recommendations may not be sufficient to prevent weight gain during the freshman year.

Step goals of 10,000 and 12,500 seemed to be well tolerated and achievable by most participants. However, exceeding 12,500 steps per day was more challenging to achieve. Even though achieving this recommendation was a struggle, the 15,000-step recommendation resulted in significantly more steps on average than was seen with lower recommendations.

While this study did observe weight gain, the composition of the weight gain was primarily lean tissue (56\% lean tissue and $44 \%$ adipose tissue). This was unexpected, since a higher proportion of weight gain as lean mass is atypical and other studies tend to indicate that weight gain in college is primarily realized as body fat rather than lean mass. For example, Morrow et al. found that the composition of the weight gain observed during the freshman year in women was $73 \%$ fat [8]. It is possible that since 10,000 steps per day is considered "Active" [25], and all the women in the study were assigned at least 10,000 steps per day, there might be a benefit for all the women in the study. While the classification of "Active" makes no reference to the quality of steps being taken, women who get 10,000 steps per day in this study accumulated 67 minutes of MVPA daily on average.

Although weight was not affected by the intervention in the study, there was a positive impact on physical activity patterns that may have other emotional and health benefits. One positive outcome of the study was that sedentary time was drastically reduced in both the 12,500- and 15,000-step groups over the academic year. In the 15,000-step group, sedentary time decreased by as much as 77 minutes/day. While this may not have been sufficient to prevent weight gain, the benefits of decreasing sedentary time have been shown in other studies to reduce cardiometabolic and inflammatory biomarkers [30] as well as reduction in risk of anxiety and depression [31, 32].

While our study makes a significant contribution to the literature on the effects of physical activity on college weight gain, it is important to address the limitations that are associated with the study. One limitation of this study was that there was no control group. This limits the interpretation of the study, since we are unable to determine if the weight gain observed in the study would have been more or less without any intervention. Additionally, we did not evaluate step counts lower than 10,000 step per day. It is possible that lower step recommendations may have allowed us to see more effects on weight, or if there was a plateauing effect on weight after 10,000 steps per day. Another limitation was that there was an unequal dropout rate and attrition in the 15,000 -step group was more drastic than the 10,000- and 12,500 -step groups, even though no participant was dismissed from the study for not meeting their step goals. While this level of attrition should be considered when interpreting the results of the study, it is a common problem with demanding physical activity interventions [33]. In addition, adherence to the 15,000-step count was challenging, especially at the beginning of the study. Participants were more compliant to their step recommendations over time but as a group never averaged 15,000 steps per day. Also, participants were not restricted on the number of daily steps. Participants 
were given a minimum goal, but they could exceed this goal. There were participants in the 10,000- and 12,500-step counts who consistently exceeded their step recommendation. However, it was not feasible to tell the participants to stop walking after they met their assigned step goals. Finally, measuring diet is difficult and underreporting energy intake is common. While 24-hour recalls are nonreactive and have been validated for assessing dietary intake, all methods of measuring diet have their limitations.

Our study makes a meaningful contribution to the literature on freshman weight gain by evaluating three different step recommendations of progressively higher volumes and these recommendations progressively increased by $25 \%$. This is supported by objectively measured and downloaded step data for every day of the study rather than subjective self-reported data. In addition, our study was unique in that it looked at attenuating weight gain in a population at risk of weight gain rather than weight loss. Finally, we used accelerometers to better describe the quantity and quality of the step interventions.

\section{Conclusions and Future Research}

The results of this study suggest that going progressively beyond 10,000 steps per day has a positive impact on physical activity patterns but does not prevent weight gain in freshman women. Setting step goals can habitually increase MVPA and decrease sedentary time. In fact, the recommendation of 15,000 steps per day resulted in over an hour more activity each day. Although prevention of weight gain was not achieved, the reduced sedentary time was substantial and has benefits that likely extended beyond weight management.

Preventing weight gain during the freshman year continues to be an important topic of research. Weight gain is accelerated during this transitional time in life. Results from this study suggest that increasing habitual steps per day is not sufficient to accomplish this goal. Future research will likely have to evaluate different dietary and behavioral strategies together to prevent weight gain or evaluate physical activity of a greater volume and/or intensity.

\section{Data Availability}

The data used to support the findings of this study are available from the corresponding author upon request.

\section{Additional Points}

Implications and Contributions. Weight gain is common during the first academic year of college. Physical activity has been found to have a positive impact on weight gain. Findings suggest that progressing beyond 10,000 steps per day has positive impacts on physical activity patterns but does not prevent weight gain in freshmen women.

\section{Conflicts of Interest}

The authors declare that they have no conflicts of interest.

\section{Authors' Contributions}

$\mathrm{BB}$ was involved in all aspects of the study and is the one who initiated the original structure and design of the study; $\mathrm{CB}$ contributed to the data analysis, interpretation of the finding, and drafting of the manuscript; CS assisted the primary and secondary authors in drafting the manuscript and presenting the data; LD assisted in drafting the manuscript and critically reviewing the paper before submission; SC assisted in designing the study, data collection/management, and drafting the manuscript; LT assisted in designing the study, data analysis, and critically reviewed the manuscript for submission; JL assisted in designing the study and critically reviewed the manuscript for submission; $\mathrm{JH}$ assisted in drafting the manuscript.

\section{Acknowledgments}

We would like to thank all the participants who gave their time to participate in this study. We also like to acknowledge all the research assistants for helping with data collection and participant recruitment. The study was funded by a Mentoring Environments Grant from Brigham Young University.

\section{References}

[1] D. A. Anderson, J. R. Shapiro, and J. D. Lundgren, "The freshman year of college as a critical period for weight gain: an initial evaluation," Eating Behaviors, vol. 4, no. 4, pp. 363-367, 2003.

[2] D. J. Hoffman, P. Policastro, V. Quick, and S.-K. Lee, "Changes in body weight and fat mass of men and women in the first year of college: a study of the "freshman 15"," Journal of American College Health, vol. 55, no. 1, pp. 41-46, 2006.

[3] S. B. Racette, S. S. Deusinger, M. J. Strube, G. R. Highstein, and R. H. Deusinger, "Changes in weight and health behaviors from freshman through senior year of college," Journal of Nutrition Education and Behavior, vol. 40, no. 1, pp. 39-42, 2008.

[4] C. L. Bish, H. M. Blanck, M. K. Serdula, M. Marcus, H. W. Kohl, and L. K. Khan, "Diet and physical activity behaviors among Americans trying to lose weight: 2000 behavioral risk factor surveillance system," Obesity Research, vol. 13, no. 3, pp. 596-607, 2005.

[5] B. W. Bailey, P. Borup, J. D. LeCheminant, L. A. Tucker, and J. Bromley, "Examining the relationship between physical activity intensity and adiposity in young women," Journal of Physical Activity and Health, vol. 12, no. 6, pp. 764-769, 2015.

[6] B. W. Bailey, P. Borup, L. Tucker, J. LeCheminant, M. Allen, and W. Hebbert, "Steps measured by pedometry and the relationship to adiposity in college women," Journal of Physical Activity and Health, vol. 11, no. 6, pp. 1225-1232, 2014.

[7] B. W. Bailey, L. A. Tucker, T. R. Peterson, and J. D. LeCheminant, "A prospective study of physical activity intensity and change in adiposity in middle-aged women," American Journal of Health Promotion, vol. 21, no. 6, pp. 492-497, 2007.

[8] M. L. Morrow, K. C. Heesch, M. K. Dinger, H. R. Hull, A. W. Kneehans, and D. A. Fields, "Freshman 15: fact or fiction?," Obesity, vol. 14, no. 8, pp. 1438-1443, 2006. 
[9] H. J. Wengreen and C. Moncur, "Change in diet, physical activity, and body weight among young-adults during the transition from high school to college," Nutrition Journal, vol. 8, p. 32, 2009.

[10] D. M. Bravata, C. Smith-Spangler, V. Sundaram et al., "Using pedometers to increase physical activity and improve health: a systematic review," JAMA, vol. 298, no. 19, pp. 2296-2304, 2007.

[11] B. L. Rooney, L. R. Gritt, S. J. Havens, M. A Mathiason, and E. A Clough, "Growing healthy families: family use of pedometers to increase physical activity and slow the rate of obesity," WMJ, vol. 104, pp. 54-60, 2005.

[12] K. K. Clarke, J. Freeland-Graves, D. M. Klohe-Lehman, T. J. Milani, H. J. Nuss, and S. Laffrey, "Promotion of physical activity in low-income mothers using pedometers," Journal of the American Dietetic Association, vol. 107, no. 6, pp. 962-967, 2007.

[13] J. D. LeCheminant, J. D. Smith, N. K. Covington et al., "Pedometer use in university freshmen: a randomized controlled pilot study," American Journal of Health Behavior, vol. 35, pp. 777-784, 2011.

[14] C. Tudor-Locke and D. R. Bassett Jr., "How many steps/day are enough? Preliminary pedometer indices for public health," Sports Medicine, vol. 34, no. 1, pp. 1-8, 2004.

[15] J. Speakman, D. Booles, and R. Butterwick, "Validation of dual energy X-ray absorptiometry (DXA) by comparison with chemical analysis of dogs and cats," International Journal of Obesity, vol. 25, no. 3, pp. 439-447, 2001.

[16] P. A. Tataranni, D. J. Pettitt, and E. Ravussin, "Dual energy X-ray absorptiometry: inter-machine variability," International Journal of Obesity and Related Metabolic Disorders, vol. 20, pp. 1048-1050, 1996.

[17] B. W. Bailey, G. LeCheminant, T. Hope, M. Bell, and L. A. Tucker, "A comparison of the agreement, internal consistency, and 2-day test stability of the InBody 720, GE iDXA, and BOD POD gold standard for assessing body composition," Measurement in Physical Education and Exercise Science, vol. 22, no. 3, pp. 231-238, 2018.

[18] M. P. Rothney, Y. Xia, W. K. Wacker et al., "Precision of a new tool to measure visceral adipose tissue (VAT) using dualenergy X-Ray absorptiometry (DXA)," Obesity, vol. 21, no. 1, pp. E134-E136, 2013.

[19] A. Mohammad, E. De Lucia Rolfe, A. Sleigh et al., "Validity of visceral adiposity estimates from DXA against MRI in Kuwaiti men and women," Nutrition \& Diabetes, vol. 7, no. 1, p. e238, 2017.

[20] E. A. Holbrook, T. V. Barreira, and M. Kang, "Validity and reliability of Omron pedometers for prescribed and self-paced walking," Medicine \& Science in Sports \& Exercise, vol. 41, no. 3, pp. 670-674, 2009.

[21] G. Plasqui and K. R. Westerterp, "Physical activity assessment with accelerometers: an evaluation against doubly labeled water," Obesity, vol. 15, no. 10, pp. 2371-2379, 2007.

[22] R. P. Troiano, D. Berrigan, K. W. Dodd, L. C. Mâsse, T. Tilert, and M. Mcdowell, "Physical activity in the United States measured by accelerometer," Medicine \& Science in Sports \& Exercise, vol. 40, no. 1, pp. 181-188, 2008.

[23] J. F. Nichols, P. Patterson, and T. Early, "A validation of a physical activity monitor for young and older adults," $\mathrm{Ca}$ nadian Journal of Sport Sciences, vol. 17, pp. 299-303, 1992.

[24] L. C. Masse, B. F. Fuemmeler, C. B. Anderson et al., "Accelerometer data reduction: a comparison of four reduction algorithms on select outcome variables," Medicine \& Science in Sports \& Exercise, vol. 37, pp. S544-S554, 2005.
[25] C. E. Matthew, "Calibration of accelerometer output for adults," Medicine \& Science in Sports \& Exercise, vol. 37, pp. S512-S522, 2005.

[26] A. F. Subar, S. I. Kirkpatrick, B. Mittl et al., "The automated self-administered 24-hour dietary recall (ASA24): a resource for researchers, clinicians, and educators from the National Cancer Institute," Journal of the Academy of Nutrition and Dietetics, vol. 112, no. 8, pp. 1134-1137, 2012.

[27] S. I. Kirkpatrick, A. F. Subar, D. Douglass et al., "Performance of the Automated Self-Administered 24-hour Recall relative to a measure of true intakes and to an interviewer-administered 24-h recall," The American Journal of Clinical Nutrition, vol. 100, no. 1, pp. 233-240, 2014.

[28] E. E. Lloyd-Richardson, S. Bailey, J. L. Fava, and R. Wing, "A prospective study of weight gain during the college freshman and sophomore years," Preventive Medicine, vol. 48, no. 3, pp. 256-261, 2009.

[29] K. G. Miller and J. M. Hartman, "Influence of physical activity on weight status during the first year of college," Journal of American College Health, pp. 1-5, 2019.

[30] G. N. Healy, C. E. Matthews, D. W. Dunstan, E. A. H. Winkler, and N. Owen, "Sedentary time and cardiometabolic biomarkers in US adults: NHANES 2003-06," European Heart Journal, vol. 32, no. 5, pp. 590-597, 2011.

[31] M. Teychenne, K. Ball, and J. Salmon, "Sedentary behavior and depression among adults: a review," International Journal of Behavioral Medicine, vol. 17, no. 4, pp. 246-254, 2010.

[32] M. Teychenne, S. A. Costigan, and K. Parker, "The association between sedentary behaviour and risk of anxiety: a systematic review," BMC Public Health, vol. 15, no. 1, p. 513, 2015.

[33] J. E. Donnelly, E. P. Kirk, D. J. Jacobsen, J. O. Hill, D. K. Sullivan, and S. L. Johnson, "Effects of 16 mo of verified, supervised aerobic exercise on macronutrient intake in overweight men and women: the midwest exercise trial," The American Journal of Clinical Nutrition, vol. 78, no. 5, pp. 950-956, 2003. 


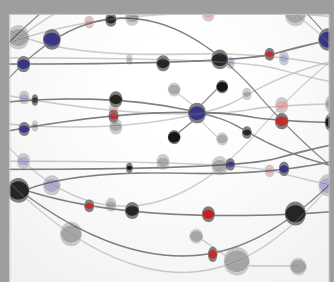

The Scientific World Journal
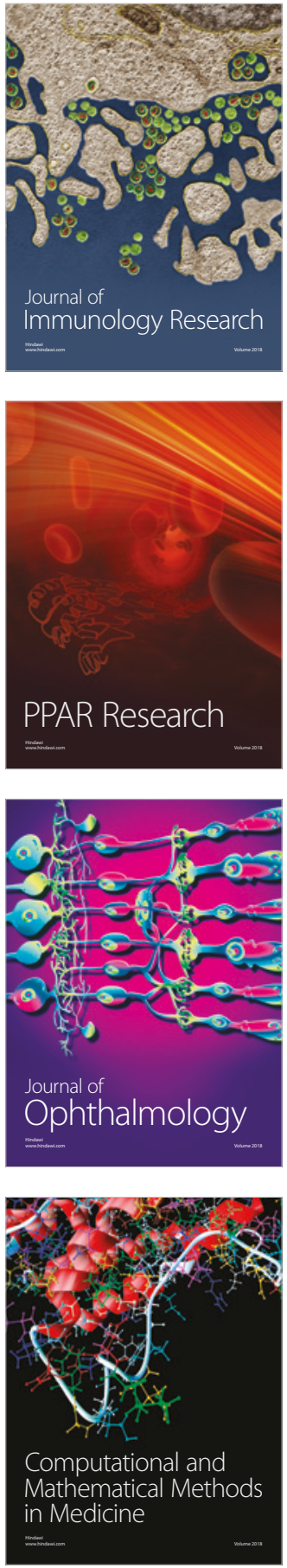

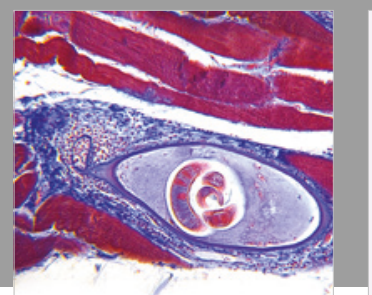

Gastroenterology Research and Practice

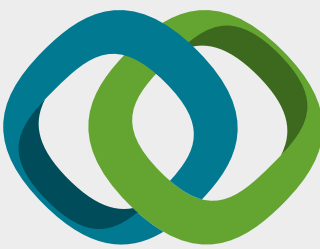

\section{Hindawi}

Submit your manuscripts at

www.hindawi.com
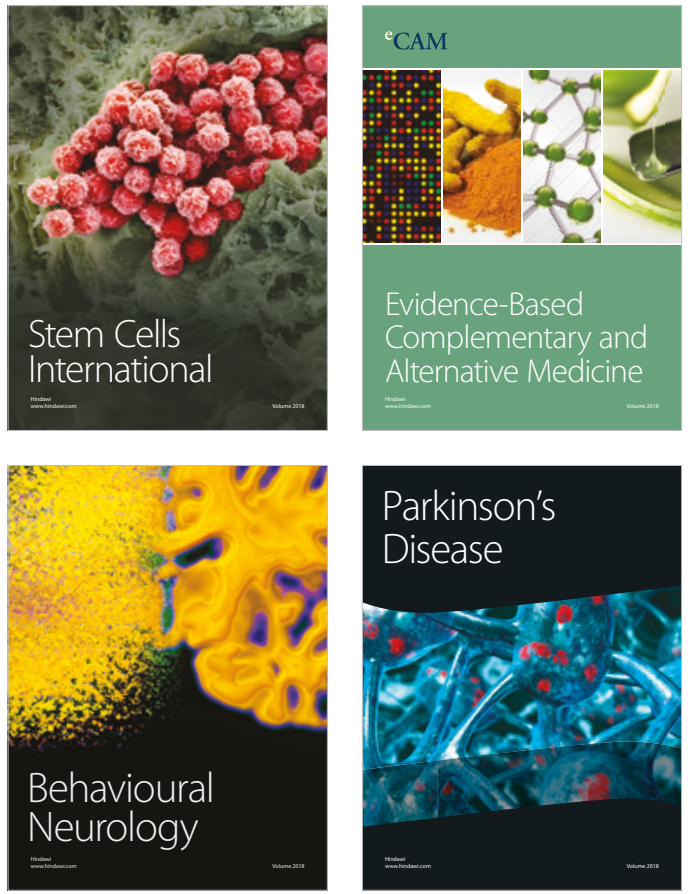

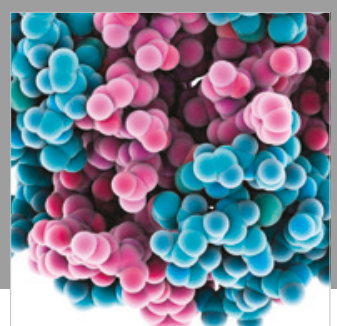

ournal of

Diabetes Research

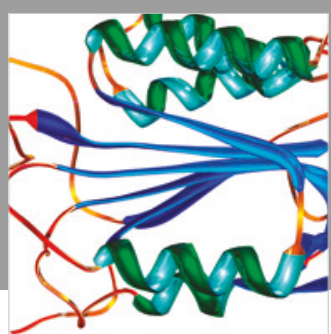

Disease Markers
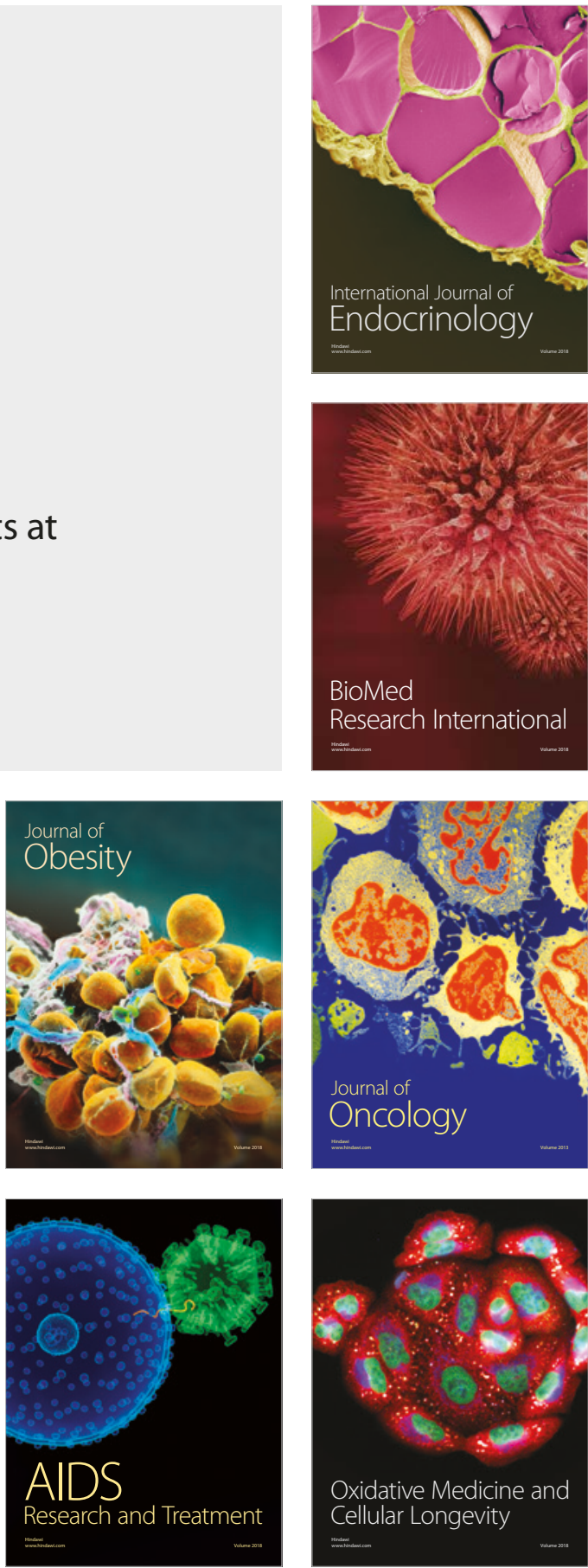